\title{
Optic Flow Input to the Hippocampal Formation from the Accessory Optic System
}

\author{
Douglas R. W. Wylie, ${ }^{1}$ Randal G. Glover, ${ }^{1}$ and John D. Aitchison ${ }^{2}$ \\ ${ }^{1}$ Department of Psychology, University of Alberta, Edmonton, Alberta, Canada, T6G 2E1, and 2Department of Cell \\ Biology and Anatomy, University of Alberta, Edmonton, Canada, T6G 2H7
}

Recent studies in rodents have implicated the hippocampal formation in "path integration": the ability to use self-motion cues (ideothesis) to guide spatial behavior. Such models of hippocampal function assume that self-motion information arises from the vestibular system. In the present study we used the retrograde tracer cholera toxin subunit $B$, the anterograde tracer biotinylated dextran amine, and standard extracellular recording techniques to investigate whether the hippocampal formation [which consists of the hippocampus proper and the area parahippocampalis (Hp/APH) in pigeons] receives information from the accessory optic system (AOS). The AOS is a visual pathway dedicated to the analysis of the "optic flow fields" that result from self-motion. Optic flow constitutes a rich source of ideothetic information that could be used for navigation. Both the nucleus of the basal optic root (nBOR) and nucleus lenti-

Recent studies have suggested that the hippocampal formation is involved in "path integration" (Foster et al., 1989; Wilson and McNaughton, 1993; McNaughton et al., 1995, 1996; Whishaw et al., 1997; Whishaw and Maaswinkel, 1998). This is a mechanism in which an animal can determine spatial relations such as starting point, destination, and present location based on information from self-motion, or "ideothetic" cues, and in the absence of external or "allothetic" cues (Mittelstaedt and Mittelstaedt; 1980; Whishaw et al., 1997; Whishaw and Maaswinkel, 1998). Whishaw and Maaswinkel (1998) showed that the use of self-motion to solve spatial problems by path integration was impaired after lesions of the fimbria-fornix. McNaughton et al. (1996) and Sharp et al. (1995) have shown that the activity of hippocampal cells is reflective, at times, of ideothetic cues, and the establishment of "place cells" depends on self-motion (Foster et al., 1989).

Information about one's self-motion through the environment can be conveyed by many sensorimotor systems, including the vestibular, somatosensory, and visual systems. That vision can serve as a proprioceptive sense was emphasized by Gibson (1950, 1954), who noted that because the environment consists of numerous stationary visual stimuli, self-motion results in "optic flow fields" across the retina. The accessory optic system (AOS), which

Received Dec. 18, 1998; revised March 25, 1999; accepted April 19, 1999.

This research was supported by grants from National Sciences and Engineering Research Council of Canada (NSERC) and the Alberta Heritage Foundation for Medical Research (AHFMR) to D.R.W. We thank Drs. D. Treit and I. Q. Whishaw for their comments on an earlier version of this manuscript.

Correspondence should be addressed to Douglas R. Wong-Wylie, Department of Psychology, University of Alberta, Edmonton, Alberta, Canada T6G 2E1.

Copyright (C) 1999 Society for Neuroscience $0270-6474 / 99 / 195514-14 \$ 05.00 / 0$ formis mesencephali of the AOS were shown to project to the area ventralis of Tsai (AVT), which in turn was shown to project to the Hp/APH. A smaller direct projection from the nBOR pars dorsalis to the hippocampus was also revealed. During extracellular recording experiments, about half of the cells within the AVT responded to optic flow stimuli. Together these results illustrate that the $\mathrm{Hp} / \mathrm{APH}$ receives information about selfmotion from the AOS. We postulate that this optic flow information is used for path integration. A review of the current literature suggests that an analogous neuronal circuit exists in mammals, but it has simply been overlooked.

Key words: hippocampus; optic flow; self-motion; path integration; accessory optic system; area ventralis of Tsai; ideothesis

is found in all vertebrate classes, is a distinct visual pathway dedicated to the analysis of optic flow fields (for review see, Simpson, 1984; Simpson et al., 1988a; Grasse and Cynader, 1990). Numerous electrophysiological studies have shown that neurons in the AOS exhibit direction selectivity in response to large visual stimuli moving in the contralateral visual field (Wylie and Frost, 1990a, 1996), and some neurons have binocular receptive fields that encode optic flow fields resulting from either self-translation or self-rotation (Graf et al., 1988; Leonard et al., 1988; Simpson et al., 1988b; Wylie and Frost, 1990b, 1991, 1993, 1999; Wylie et al., 1998a).

Studies implicating the hippocampal formation in path integration consider that self-motion arises from the vestibular system (McNaughton et al., 1996), but one might expect that the hippocampal formation receives optic flow input from the AOS. In pigeons, Casini et al. (1986) showed that the hippocampal formation [which in birds consists of the hippocampus proper (Hp) and area parahippocampalis (APH)] receives input from a group of cells in the ventral tegmentum in the vicinity of the third cranial nerve, a region known as the area ventralis of Tsai (AVT). We have reported previously that the nucleus of the basal optic root (nBOR) projects to the ventral tegmentum (Wylie et al., 1997). These terminals were not found in any clearly defined nucleus, but we ascribed some of these to the lateral extension of the AVT. In the present study we did a series of anterograde, retrograde, and double labeling studies to determine whether the region in the ventral tegmentum containing $\mathrm{Hp} / \mathrm{APH}$-projecting neurons receives input from the AOS. In addition, with extracellular recording techniques, we examined the responsiveness of neurons in the AVT to optic flow stimuli. 


\section{MATERIALS AND METHODS}

Surgery. The methods reported herein conformed to the guidelines established by the Canadian Council on Animal Care and were approved by the Biosciences Animal Care and Policy Committee at the University of Alberta. These guidelines ensured that efforts were made to minimize both animal discomfort and the number of animals used. Experiments were performed on Silver King pigeons anesthetized intramuscularly with a ketamine $(90 \mathrm{mg} / \mathrm{kg}) /$ xylazine $(15 \mathrm{mg} / \mathrm{kg})$ mixture. Supplemental doses were administered as necessary. The animals were placed in a stereotaxic device with pigeon ear bars and beak adapter such that the orientation of the skull conformed with the atlas of Karten and Hodos (1967).

Anterograde tracing studies. Anterograde tracing studies were performed by iontophoretically injecting biotinylated dextran amine (BDA) into either the nBOR (four birds) or the pretectal nucleus lentiformis mesencephali (LM) (five birds). The nBOR and LM are the two retinalrecipient nuclei of the avian AOS (Karten et al., 1977; Reiner et al., 1979; Fite et al., 1981; Gamlin and Cohen, 1988a). These nuclei were located using stereotaxic coordinates in Karten and Hodos (1967), and sections of bone and dura were removed to expose the penetration site. On initial penetrations, extracellular recordings were made with glass microelectrodes (4-5 $\mu \mathrm{m}$ tip diameter) filled with $2 \mathrm{M} \mathrm{NaCl}$. Sensitivity of isolated cells to optic flow stimuli was determined by moving a large $\left(90^{\circ} \times 90^{\circ}\right)$ hand-held stimulus, consisting of a pattern of random dark lines and dots on a light background. LM and nBOR neurons have large receptive fields in the contralateral eye. Most nBOR neurons prefer upward, downward, or backward (nasal to temporal) motion of such large-field stimuli (Wylie and Frost, 1990a), whereas most LM neurons prefer forward (temporal to nasal) motion (Winterson and Brauth, 1985; Wylie and Frost, 1996). Once cells sensitive to large-field motion were found, the recording electrode was replaced with a glass micropipette (tip diameter of 10-12 $\mu \mathrm{m}$ ) filled with BDA (Molecular Probes; $10 \%$ in $0.1 \mathrm{M}$ PBS), which was injected iontophoretically ( $+3 \mu \mathrm{A}, 1 \mathrm{sec} \mathrm{ON}, 1 \mathrm{sec} \mathrm{OFF}$ ) for 2-5 min. Recordings were first made with the BDA electrode to ensure that the injection was within LM or nBOR. Subsequent to the injection the electrode was left undisturbed for $5 \mathrm{~min}$. After a survival time of 3-6 d, the animals were given an overdose of sodium pentobarbitol $(100 \mathrm{mg} / \mathrm{kg})$ and immediately perfused with saline $(0.9 \%)$ followed by $4 \%$ paraformaldehyde in $0.1 \mathrm{~m}$ phosphate buffer (PB). The brains were extracted, post-fixed for $2-6 \mathrm{hr}$ (4\% paraformaldehyde, $20 \%$ sucrose in $0.1 \mathrm{M} \mathrm{PB}$ ), and cryoprotected in sucrose overnight (20\% in $0.1 \mathrm{M} \mathrm{PB})$, and frozen sections in the coronal plane ( $40 \mu \mathrm{m}$ thick) were collected. The BDA protocol used was based on the procedure of Wild (1993). Sections were washed in PBS, incubated in $1 \% \mathrm{H}_{2} \mathrm{O}_{2}$ with $25 \%$ methanol for $20 \mathrm{~min}$, washed in $0.1 \mathrm{M}$ PBS, incubated in ExtrAvidin peroxidase (Sigma, St. Louis, MO; $1: 1000)$ with Triton X-100 $(0.4 \%)$ for $1.5 \mathrm{hr}$ at room temperature, washed in PBS, then visualized with diaminobenzidine (DAB) using cobalt chloride intensification. After $10 \mathrm{~min}$ in $0.025 \% \mathrm{DAB}$ in 0.1 M PBS with $0.002 \% \mathrm{CoCl}_{2}, 0.005 \% \mathrm{H}_{2} \mathrm{O}_{2}$ was added, and the tissue was reacted for up to $2 \mathrm{~min}$. The sections were subsequently washed several times in PBS, mounted on gelatin-coated slides, dried, lightly counterstained with Neutral Red, and coverslipped with Permount.

Retrograde tracing studies of the AVT. To confirm these anterograde studies, unilateral injections of the retrograde tracer cholera toxin subunit B (CTB) were made in the AVT in three animals. The AVT was located stereotaxically, and extracellular recordings were used to locate optic flow-sensitive cells for injection, as described for anterograde tracing procedures. In two birds, CTB (Sigma; $1 \%$ in Tris buffer) in glass micropipettes (tip diameter $16-20 \mu \mathrm{m}$ ) was pressure-injected using a PicoSpritzer II (General Valve Corp.). For the remaining bird, an iontophoretic injection of CTB was made $(+3 \mu \mathrm{A}, 7 \mathrm{sec}$ ON, $7 \mathrm{sec}$ OFF, 2-5 min) to allow for a smaller injection in the AVT and prevent inclusion of the nearby nucleus ruber $(\mathrm{Ru})$, which also receives projections from nBOR and LM (Gamlin and Cohen, 1988b; Wylie et al., 1997). A buffer exchange was necessary to use CTB for iontophoresis and was performed as described by Luppi et al. (1990) to yield a 1\% CTB in $0.1 \mathrm{M}$ PB, which was injected iontophoretically. The electrode was left undisturbed for $5 \mathrm{~min}$ after injection. The CTB visualization protocol we used was based on Wild (1993). After a survival period of 2-5 d, the birds were perfused, and the brain was sectioned as described above for BDA processing. Sections were washed in PBS (three times for $10 \mathrm{~min}$ ), incubated in $1 \% \mathrm{H}_{2} \mathrm{O}_{2}$ with $25 \%$ methanol for $20 \mathrm{~min}$, and then washed in $0.1 \mathrm{M}$ PBS. The tissue was then incubated for $30 \mathrm{~min}$ in $4 \%$ rabbit serum (Sigma; in PBS) with $0.4 \%$ Triton X-100, followed by goat antiCHB (List Biological Laboratories; 1:20000 in PBS) with 0.4\% Triton $\mathrm{X}-100$ for $20-24 \mathrm{hr}$ at $4^{\circ} \mathrm{C}$. The tissue was washed with $0.1 \mathrm{M} \mathrm{PBS}$ and then placed in biotinylated rabbit anti-goat (Vector Laboratories; 1:600 in PBS) with $0.4 \%$ Triton X-100 for $1 \mathrm{hr}$, washed with PBS, placed in ExtrAvidin with $0.4 \%$ Triton X-100 for $1.5 \mathrm{hr}$, rinsed with PBS, and visualized with $\mathrm{DAB}$ as described for the BDA procedure. The sections were mounted on gelatin-coated slides, dried, lightly counterstained with Geimsa, and coverslipped with Permount.

Retrograde tracing studies of the $H p / A P H$. To verify previous studies showing a projection from the AVT to the hippocampal formation (Casini et al., 1986), two birds received bilateral pressure injections of CTB that included the Hp and APH. The Hp/APH was located using stereotaxic coordinates in Karten and Hodos (1967). The tissue was processed for CTB as described above.

Double labeling studies. Two birds were used for double labeling experiments involving a unilateral BDA injection into the nBOR and bilateral CTB pressure injections in the Hp/APH. The surgery and injection procedures used were identical to those described above. The visualization process we used was based on the protocol described by Wild (1993). The tissue was first processed for BDA and visualized using the cobalt chloride-intensified DAB reaction described above. Subsequently the tissue was processed for CTB as described above, but was visualized using $\mathrm{DAB}$ without cobalt chloride. The resulting reactions turned BDA anterograde labeling from nBOR dark brown or black, whereas the retrogradely labeled cells from the Hp/APH were light brown.

Extracellular recording studies. In three animals, using tungsten microelectrodes, extracellular recording studies investigated the responses of cells in the nBOR and AVT to optic flow stimuli. Using the stereotaxic atlas as a guide, we first penetrated the nBOR and recorded from isolated neurons. Subsequent tracks were made at more medial locations such that we could access the AVT. In some instances the penetration was performed with the electrode oriented $5^{\circ}$ to the midline to permit easier access to the AVT. (For detailed descriptions of our electrophysiological methods see Wylie and Frost, 1990a,b, 1991, 1993, 1999; Wylie et al., 1998a). Single units were initially tested for optic flow sensitivity using the large hand-held stimulus. Both the ipsilateral and contralateral receptive fields were tested. The responses of cells with monocularcontralateral receptive fields to large-field motion (velocity $0.6-20 \% \mathrm{sec}$ ) in various directions in the contralateral hemifield were measured. Those cells found to be sensitive to large-field motion in both hemifields were studied further using the "translator" and "planetarium" projectors described by Wylie et al. (1998a) and Wylie and Frost (1993, 1999). These projectors cast patterns of dots on the walls, ceiling, and floor of the room and simulated translational (translator) and rotational (planetarium) optic flow fields. The axis of translation or rotation could be adjusted to any orientation within three-dimensional space. The speed of the dots in the flow fields was in the range of $0.3-10^{\circ} / \mathrm{sec}$. Peristimulus time histograms (PSTHs) were summed from 5-20 sweeps using Spike 2 software (Cambridge Electronic Designs). Marking lesions were made at some recording sites ( $30 \mu \mathrm{A}$, electrode negative, $5-10 \mathrm{sec})$. To verify the lesion sites, the birds were perfused at the end of the recording session, the brains were extracted, and frozen sections were collected through the AVT. These sections were mounted on gelatin-coated slides, stained, coverslipped in Permount, and examined using light microscopy.

Nomenclature. The pigeon $\mathrm{nBOR}$ is located at the base of the brain at the mesodiencephalic border and receives direct retinal input from the displaced ganglion cells (Karten et al., 1977; Reiner et al., 1979; Fite et al., 1981). Brecha et al. (1980) divided the nBOR into three subgroups based on cell morphology and spatial location. The bulk of the nucleus, nBOR proper (nBORp), consists mainly of large- and medium-sized round cells and a smaller number of small spindly cells. The nBOR dorsalis (nBORd), consisting of a thin layer of small spindly cells, lines the caudal and dorsal margins of the nBORp. The nBOR lateralis $(\mathrm{nBOR} 1)$ is a small group of cells located dorsal to the stratum opticum (Sop) and lateral to the rest of the nucleus. McKenna and Wallman (1981, 1985a) showed that the nBOR 1 is contiguous with and functionally similar to the LM.

In pigeons, the pretectum consists of numerous nuclei, the borders of which are difficult to define. We use the description by Gamlin and Cohen (1988a). The LM consists of two subnuclei, the LM pars lateralis (LMl) and the LM pars medialis (LMm). Medial to the LMm is a strip of small cells, the nucleus laminaris precommissuralis (LPC), which appears contiguous with the internal lamina of the nucleus geniculatus lateralis, pars ventralis (GLv). Medial to the LPC is the nucleus principalis precommissuralis (PPC), which resides lateral to the nucleus rotun- 
dus (Rt). Ventrally, the LMm, LMl, and LPC course ventral to the nucleus subpretectalis (SP) and posterior to the GLv. The LMm and $\mathrm{LMl}$, although virtually indistinguishable at this point, continue medially as a strip of cells that becomes the nBOR1.

\section{RESULTS Retrograde studies of the Hp/APH}

In two birds the hippocampal formation $(\mathrm{Hp} / \mathrm{APH})$ received a bilateral pressure injection of CTB (cases HF1 and HF2). The distribution of retrogradely labeled cells was similar to that reported by Casini et al. (1986). Figure 1 shows drawings of serial sections from case HF2, illustrating the injection site and retrograde labeled cells in the AVT. Labeled cells were found throughout the rostrocaudal extent of the AVT, most heavily adjacent to the third cranial (oculomotor) nerve (Fig. 2A, $B$, $I I I)$. In both cases several cells were also found in nBORd. This previously unreported result suggests a small direct link between the nBOR complex and the hippocampal formation (Figs. 1C, 2B).

\section{Anterograde tracing studies}

Previous studies have described projections of the nBOR and LM. The most extensive projection of the nBOR is to the ipsilateral $\mathrm{LM}$, but $\mathrm{nBOR}$ projects to numerous other structures including the cerebellum, vestibular nuclei, inferior olive, pontine nuclei, contralateral nBORd, oculomotor complex, mesencephalic reticular formation $(\mathrm{RF})$, nucleus ruber $(\mathrm{Ru})$, accessory oculomotor nuclei [nucleus Darkschewitsch (D), the interstitial nucleus of Cajal (IC), and central gray $(\mathrm{CtG})]$, and dorsal thalamus (Brecha et al., 1980; Wylie and Linkenhoker, 1996; Wylie et al., 1997, 1998b). The most extensive projection of the LM is to the ipsilateral nBOR, and previous studies have reported that LM also projects to the cerebellum, inferior olive, pontine nuclei, D, IC, CtG, Ru, and dorsal thalamus (Clarke, 1977; Gamlin and Cohen, 1988a; Wild, 1989; Wylie et al., 1998b). For the present study we describe only projections of the LM and nBOR to the hippocampal projection area in the ventral tegmentum.

The LM was injected with BDA in five cases. All five injections were centred on LMl but also included the LMm. Injection LM1 was centered on ventral LM and also included LPC and PPC. Injection LM2 was centered on and confined to dorsal LM. Injection LM3 was also dorsal and included LPC, PPC, and the tectal gray. LM4 was located in rostral ventral LM and also included the tectal gray, LPC, and PPC. Injection LM5 was again centered on ventral LM and encroached slightly on the tectal gray. Figure 3 shows a series of sections illustrating the injection site and terminal labeling in the AVT from case LM5. The injection site in the ventral LM is shown by the blackened area in $A$ and $B$. In these sections terminal labeling was found throughout the pretectum, and some terminal labeling was found in the optic tectum (TeO), RF, D, CtG, the lateral division of the anterior dorsolateral thalamus (DLL), and adjacent to nucleus subpretectalis (SP), and the medial and lateral spiriform nuclei (SpL/M). The majority of the labeling in these sections resulted from a massive fiber bundle that coursed medially from the injection site along the top of the optic tract ( $\mathrm{TrO}$ ) and traveled just posterior to the GLv. Terminals from these fibers were seen in the ventromedial portion of $\mathrm{LM}(A-C), \mathrm{GLv}(A, B)$, and the RF just dorsal to the nBOR complex $(E-H)$. Terminal labeling was found in nBORp but was especially heavy in nBORl and nBORd $(C-H)$. Some of these fibers continued medially and terminated in the
AVT $(E-H)$. This pattern of terminal labeling was common to all five cases. In case LM5, terminal labeling was absent from the Ru, but sparse labeling was found here in other cases. In other cases a few terminals in the AVT arose from fibers that descended through the RF (Fig. 4B). Terminals in the AVT were most abundant ventrally, just medial to the nBOR and lateral to III, but very few terminals were found adjacent to the dorsal margin of III. Overall, labeling within the AVT was heavier when the injection was located in the ventral rather than dorsal LM, and terminal labeling in the AVT was less from the LM injections compared with the nBOR injections (see below). Figure $4 A, B$ shows the terminal fields of fibers, from cases LM3 and LM4, respectively, that were reconstructed from serial sections with the aid of a drawing tube. The fiber shown in $A$ was more typical of the fibers projecting from the LM to the AVT. This fiber terminated in the nBORp and nBORd and continued medially and terminated in the AVT. The fiber in $B$ descended from the injection site through the $\mathrm{RF}$, lateral to the $\mathrm{Ru}$, and medial to the tractus quintofrontalis (QF) and terminated in the AVT. Numerous terminals were also seen in the RF from this fiber.

The nBOR was injected in four pigeons. In each case a group of fibers traveled dorsally and medially along the lateral edge of the AVT, providing massive input to the ipsilateral $\mathrm{Ru}$ and accessory oculomotor areas, as described previously by Wylie et al. (1997). In all cases, some of these fibers gave off collaterals to the AVT. In two cases collaterals of axons, which crossed the midline either via the posterior commissure or dorsal to the AVT, terminated in the nBORd and AVT contralateral to the injection site. In case nBOR1, the injection site was located in the ventral portion of nBORp and did not include any of nBORd. Labeling in the AVT in this case was heaviest ventrally, just medial to $\mathrm{nBOR}$ and lateral to the ventral margin of III. A few terminals were also seen slightly dorsal to these and in the contralateral AVT dorsomedial to nBOR. Overall case nBOR1 showed the least AVT labeling of all nBOR injections. In case nBOR2, the injection site was centered on dorsal $\mathrm{nBORp}$ and included but did not extend beyond nBORd. Labeling within the AVT in this case was again seen ventrally but extended dorsally and medially throughout the AVT and bordered III medially and dorsally. Two sets of terminals were also found medial to III at the midline; however, none was found in the contralateral AVT. Overall, case nBOR2 showed the most AVT labeling. In cases nBOR3 and $\mathrm{nBOR} 4$, the injections were centered on the middle of nBORp and may have encroached on nBORd as well. Labeling in these cases showed a pattern similar to that seen in case nBOR2, although the extent of labeling was less. Terminals were again found in the contralateral AVT in case nBOR3, dorsomedial to nBOR. In summary, all cases of BDA injections in the nBOR showed anterogradely labeled terminals within the AVT, the majority of which were located immediately lateral to III. The greatest amount of labeling in the AVT occurred when the injection included nBORd, as in case nBOR2. Terminals were also seen, although much less frequently, in the contralateral AVT as well. Figure $4 C$ shows a fiber reconstructed from serial sections from case nBOR4. This fiber terminated in IC and $\mathrm{CtG}$, but a collateral gave off terminals in the AVT just dorsal to III.

\section{Retrograde tracing studies of the AVT}

The AVT was injected with CTB in three animals. In two cases, pressure injections were made, but in case AVT3 a small ionto- 

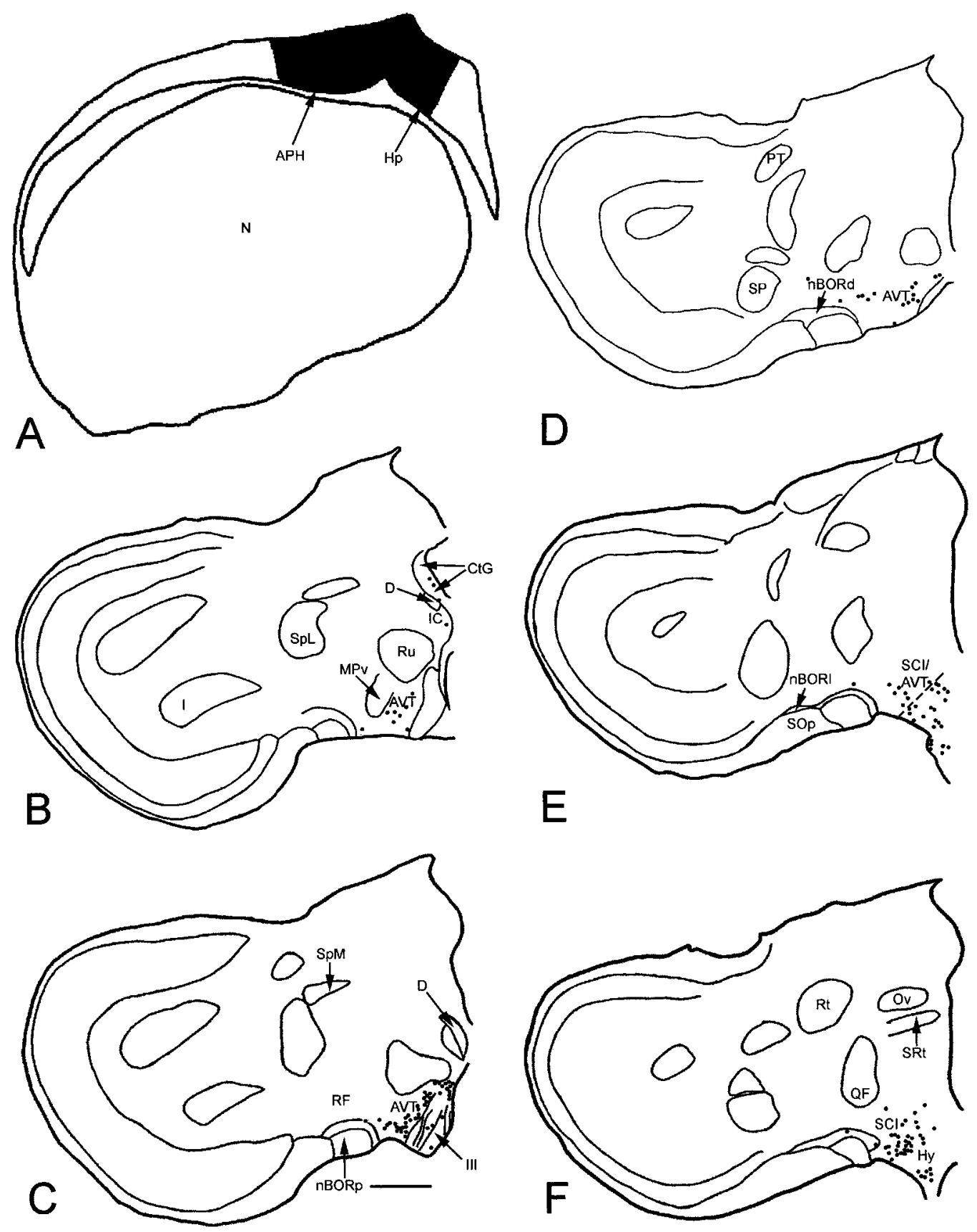

Figure 1. Retrograde labeling in the area ventralis of Tsai $(A V T)$ after a bilateral injection of cholera toxin subunit $\mathrm{B}(\mathrm{CTB})$ in the hippocampus and area parahippocampalis (Hp/APH). $A-F$, Drawings of serial sections showing the location of the injection site and retrogradely labeled cells after pressure injection of CTB. The sections shown in $B-F$ are $\sim 275 \mu \mathrm{m}$ apart. As can be seen in $A$, the injection included both Hp and APH, and in general, labeling after this injection conformed to the results shown by Casini et al. (1986). Retrograde labeling in the AVT was heaviest near the third cranial nerve (III), with retrogradely labeled cells found lateral, dorsal, and medial to III and between stria of III (as seen in $C$ ). Also note the presence of a few labeled cells in the nucleus of the basal optic root pars dorsalis $(n B O R d)$, indicating a small direct projection from this area to the hippocampal formation $(C, F)$. Ct $G$, Central gray; $D$, nucleus Darkschewitsch; $H y$, hypothalamus; $n B O R l / p$, nBOR lateralis/proper; $M P v$, nucleus mesencephalicus prof undus pars ventralis; $N$, neocortex; $O v$, nucleus ovoidalis; $P T$, nucleus pretectalis; $Q F$, tractus quintofrontalis; $R F$, mesencephalic reticular formation; $R t$, nucleus rotundus; $R u$, nucleus ruber; $S C I$, stratum cellulare internum; $S O p$, stratum opticum; $S P$, nucleus subpretectalis; $S p M / l$, nucleus spiriformis medialis/lateralis; SRt, nucleus subrotundus. Scale bar, $1 \mathrm{~mm}$.

phoretic injection was made. Figure 5 shows drawings of serial sections through the nBOR and LM from this case. The dark shaded areas in $A$ and $B$ indicate the injection site, and dots indicate the position of retrogradely labeled cells. Retrograde labeling was found bilaterally (but heavier ipsilaterally) in the
nBOR and in the ipsilateral LM, confirming results of anterograde tracing studies discussed above. Most labeling within the nBOR was located in the dorsal portions of nBORp and in nBORd (Fig. 2D,E), confirming previous observations that the BDA injection that included nBORd provided the most labeling 


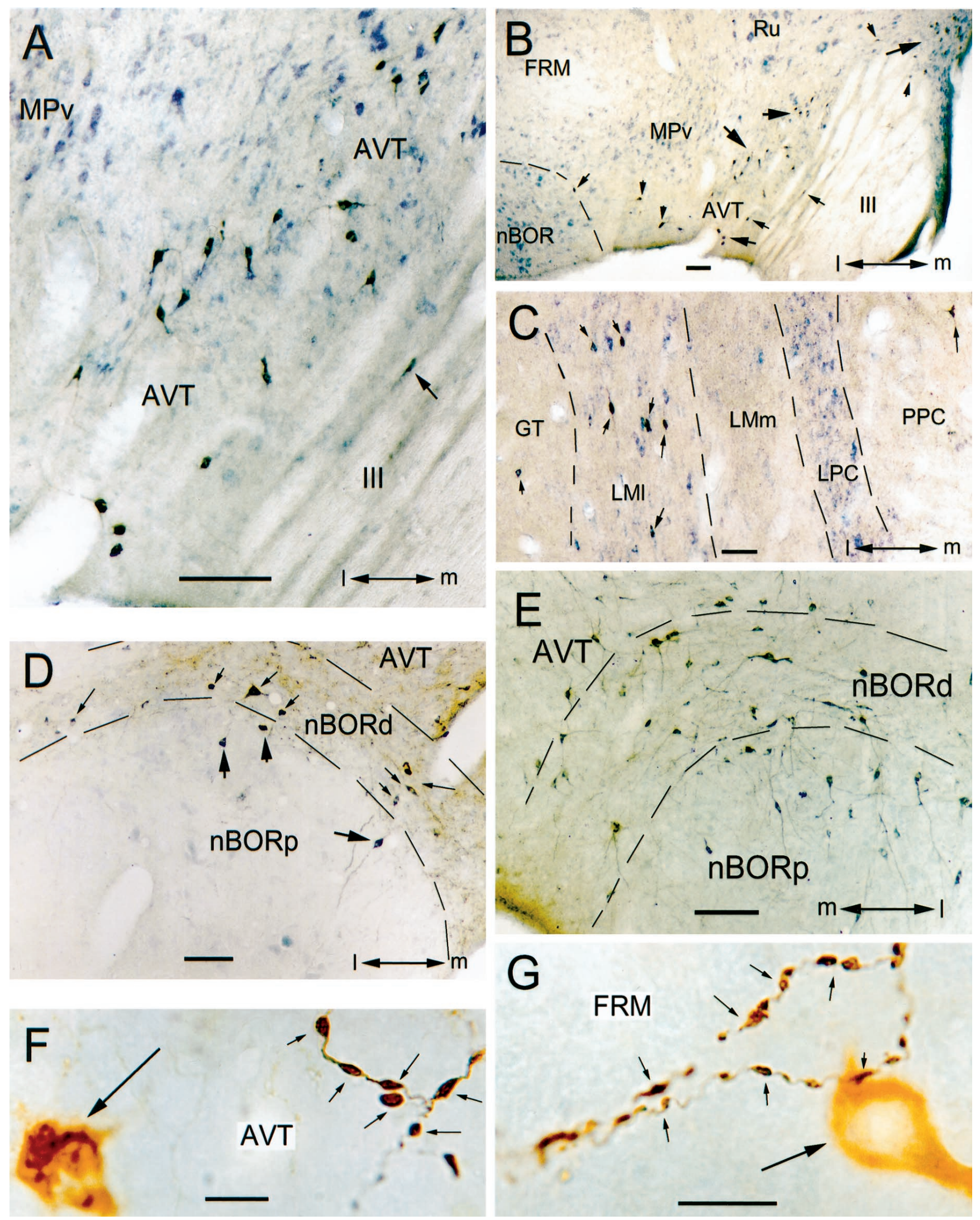

Figure 2. $A, B$, Photomicrographs of retrograde-labeled cells in the area ventralis of Tsai $(A V T)$ after injection of cholera toxin subunit B (CTB) in the hippocampus and parahippocampalis. The small arrows indicate individual cells, and the larger arrows indicate groups of several cells. Note the cells labeled in the nucleus of the basal optic root pars dorsalis $(n B O R d)$ and between stria of the third cranial nerve (III). $C$, Retrograde-labeled cells in the pretectum after iontophoretic injection of CTB in the AVT. The arrows indicate retrogradely labeled neurons, and the dotted lines show the boundaries between the pretectal nuclei. GT, Griseum tectale; $L M l / m$, nucleus lentiformis mesencephali lateralis/medialis; LPC, nucleus (Figure legend continues) 
within the AVT. Most of the labeling in the LM was found in LMl (Figs. 2C, 5E,F).

Labeling within the AOS nuclei in cases AVT1 and AVT2 was similar to that seen in AVT3, except that both injections were much larger and resulted in massive labeling of many brainstem and cortical structures as well as the AOS nuclei, indicating that the injection had included structures outside the AVT. Most problematic was the apparent inclusion of $\mathrm{Ru}$, which also receives projections from the nBOR (Wylie et al., 1997) and LM (Gamlin and Cohen, 1988b). Labeling in the external cuneate, lateral cerebellar nucleus, caudal PPC, medial spiriform nucleus, and hyperstriatum accessorium suggested that the Ru was included in the injection in both of these cases (Wild, 1992). This labeling was absent in case AVT3, and thus we are confident that the Ru was spared.

\section{Double labeling studies}

In two birds, BDA was injected unilaterally into nBOR, and CTB was injected bilaterally in the Hp/APH. In the first double labeling case (DL1), the BDA injection was centered on nBORp and included some of nBORd. The pressure injection of CTB appeared slightly smaller than previous $\mathrm{Hp} / \mathrm{APH}$ injections but did include both the $\mathrm{Hp}$ and APH bilaterally. In the second double labeling case (DL2), the BDA injection was larger, centered on dorsal nBORp, and included a substantial portion of nBORd, and there was some inclusion of the adjacent RF. The Hp/APH injections of CTB were also larger, and as a consequence both anterograde and retrograde labeling in the AVT in case DL2 was much greater than in DL1. In both cases, retrograde-labeled cells from the hippocampal injections were found intermingled with anterograde-labeled fibers from the nBOR throughout the ipsilateral AVT, but to a much greater extent in case DL2. Figure 6 shows a series of sections through the AVT from case DL2. The BDA injection site in $\mathrm{nBOR}$ is shown by the blackened area, and the locations of anterograde terminals are indicated by the small gray dots. Retrogradely labeled cells from the CTB injection into $\mathrm{Hp} / \mathrm{APH}$ (injection site not shown) are indicated by the larger black dots. In addition to the AVT, anterograde-labeled terminals and retrograde-labeled cells were intermingled in the contralateral AVT and nBORd, the ipsilateral $\mathrm{CtG}, \mathrm{D}$, stratum cellulare internum/externum (SCI/SCE), and RF. Figure $2 F, G$ shows photomicrographs of anterogradely labeled terminals near labeled cells in the AVT and medial mesencephalic reticular formation (FRM), respectively.

\section{Electrophysiological studies}

The remaining three birds were used in extracellular recording studies to investigate responses of cells in the AVT to optic flow stimuli. Previous electrophysiological studies have shown that nuclei of the AOS are ideally suited for the analysis of optic flow resulting from self-motion. Neurons in the LM and nBOR have large monocular receptive fields and respond best to large-field visual stimuli moving in a particular direction in the contralateral eye (Burns and Wallman, 1981; Winterson and Brauth, 1985; Wylie and Frost, 1990a). Some neurons in nBORd have large binocular receptive fields and respond best to visual flow fields simulating either self-translation along or self-rotation about a particular axis in three-dimensional space (Wylie et al., 1998a; Wylie and Frost, 1990b, 1999).

Figure 7 shows results from one of the recording experiments. In this experiment, we first recorded from nBOR, and subsequent penetrations were placed more medially to access the AVT. Two sections through the basal mesencephalon are shown indicating the locations of four isolated neurons that were responsive to optic flow stimulation. The upper section was located $\sim 0.5 \mathrm{~mm}$ caudal to the lower section. The cell in $B$ was located in nBORp and had a monocular-contralateral receptive field. A PSTH in response to oscillating upward and downward whole-field motion is shown (averaged from 20 sweeps). The cell was excited by upward large-field motion and inhibited by downward motion. The movement velocity was $5 \% \mathrm{sec}$, which was the preferred velocity, but the cell was modulated over the entire range tested $(0.6-20 \%$ sec). The cell in $A$ was located in nBORd and had a binocular receptive field. In response to the hand-held stimulus, this neuron was excited by backward motion in both hemifields, which normally results from forward translation of the bird. This cell was tested with the translator projector that simulated translational optic flow fields (Wylie et al., 1998a). The PSTH shows the response to translation along the $z$-axis (i.e., the flow fields resulting from forward and backward self-translation) (averaged from five sweeps). Just above the PSTH is a schematic illustration of the flow field that results from backward translation along the $z$-axis. It is best described as forward optic flow in both hemifields that converges to a point in front of the observer. The sequence for each sweep was as follows: (1) $\sim 5 \mathrm{sec}$ of backward optic flow, (2) a $5 \mathrm{sec}$ pause, (3) $5 \mathrm{sec}$ of forward optic flow, and (4) a $5 \mathrm{sec}$ pause. This cell was excited in response to backward optic flow and inhibited by forward optic flow. This cell preferred the higher velocities $(>5 \% \mathrm{sec})$ but responded across the entire range tested $\left(0.3-10^{\circ} / \mathrm{sec} ; 10^{\circ} / \mathrm{sec}\right.$ is shown).

The cells in $C$ and $D$ were localized to the caudolateral AVT and rostral AVT, respectively. Our retrograde tracing studies showed that cells in these areas project to the Hp/APH (Figs. $1 B, E, 6 A, F$ ). Like the cell in $A$, the cell in $C$ had a binocular receptive field but had the opposite direction preference. PSTHs in response to flow fields along the $z$-axis are shown for binocular as well as monocular viewing for each hemifield (each averaged from five sweeps). For both the ipsilateral and contralateral hemifields, forward optic flow resulted in excitation and backward optic flow resulted in inhibition. Thus, this neuron would respond best to the flow field resulting from backward translation. Clearly there was greater modulation in response to binocular stimulation compared with monocular stimulation of either eye alone. This cell preferred velocities $>5 \%$ sec but was responsive across the entire range tested $\left(0.3-10^{\circ} / \mathrm{sec}\right.$; $10^{\circ} / \mathrm{sec}$ is shown). The cell in $D$ had a monocular-contralateral receptive field and preferred downward motion. The PSTH shows the response to alternating upward and downward large-field mo-

$\leftarrow$

laminaris precommissuralis; $P P C$, nucleus principalis precommissuralis. Labeling was heaviest in LMl. $D$, $E$, Retrograde labeling in the ipsilateral and contralateral nBOR, respectively, after injection of CTB into AVT. Labeling after such injections was heaviest in the dorsal portions of nBOR proper $(n B O R p)$ and the adjacent nBORd. $F, G$, Anterograde-labeled fibers from nBOR terminating on or near retrograde-labeled cells in the AVT and medial mesencephalic reticular formation $(F R M)$ after a double labeling study. The visualization procedure, described by Wild (1993), stains the CTB-labeled cells light brown, whereas the BDA-labeled fibers appear dark brown or black. l, Lateral; $m$, medial. Scale bars: $A, B, D, E, 100 \mu \mathrm{m} ; C, 50 \mu \mathrm{m} ; F, G, 10 \mu \mathrm{m}$. 

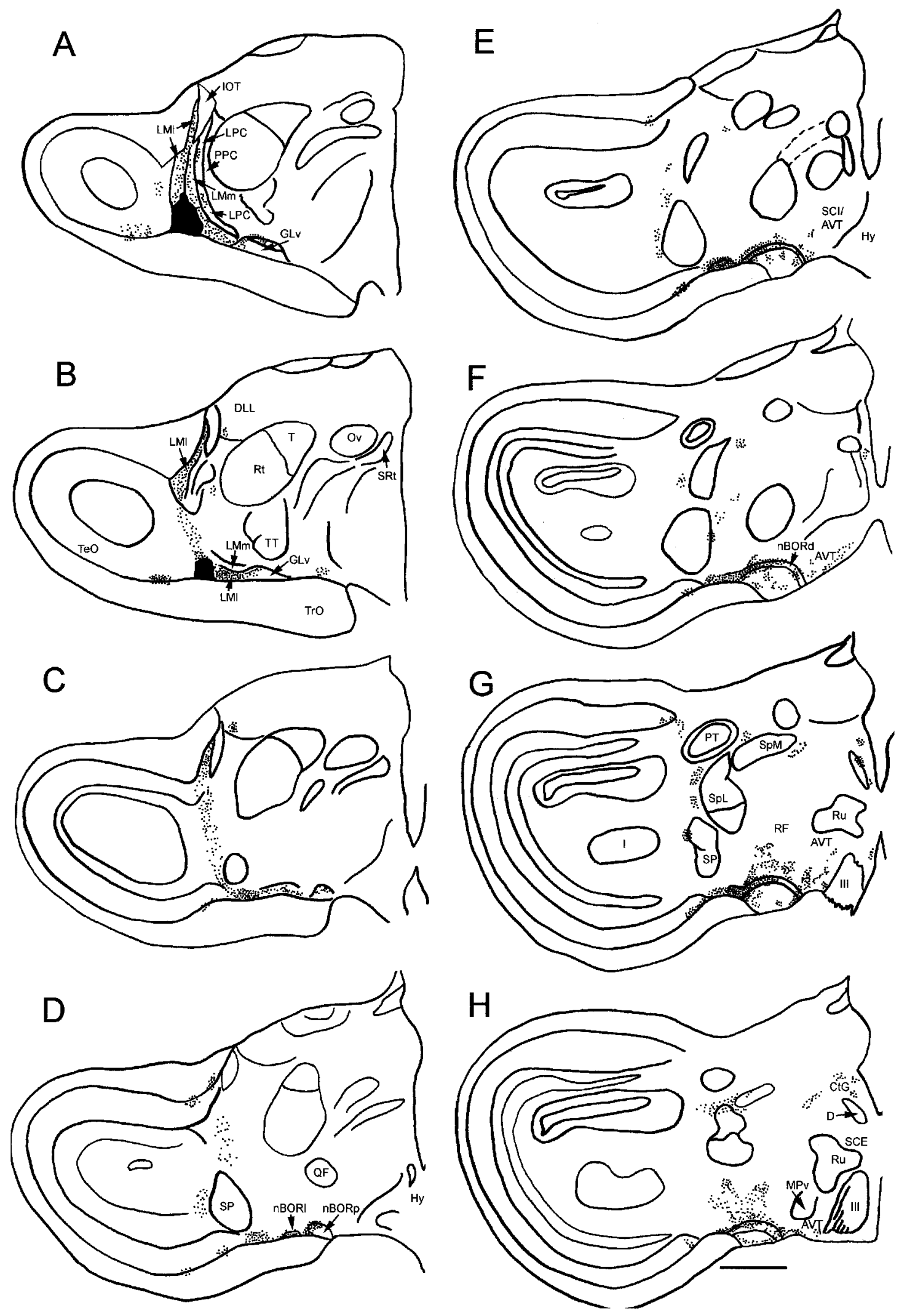

Figure 3. Anterograde labeling in the area ventralis of Tsai $(A V T)$ after injection of biotinylated dextran amine (BDA) into the pretectal nucleus lentiformis mesencephali $(L M)$. $A-H$, Series of drawings (rostral to caudal, $250 \mu \mathrm{m}$ apart) from case LM5 illustrating the injection site and terminal labeling in the AVT. The injection site is indicated by the blackened region $(A, B)$, and the dots represent the locations of terminal labeling. See Results for additional details. $D L L$, Nucleus dorsolateralis anterior thalami pars lateralis; GLv, nucleus geniculatus lateralis pars ventralis; IOT, isthmo-optic tract; $S C E$, stratum cellulare externum; $T e O$, optic tectum; $\operatorname{Tr} O$, tractus opticus; $T T$, tractus tectothalamicus. See legends to Figures 1 and 2 for other abbreviations. Scale bar, $1 \mathrm{~mm}$. 


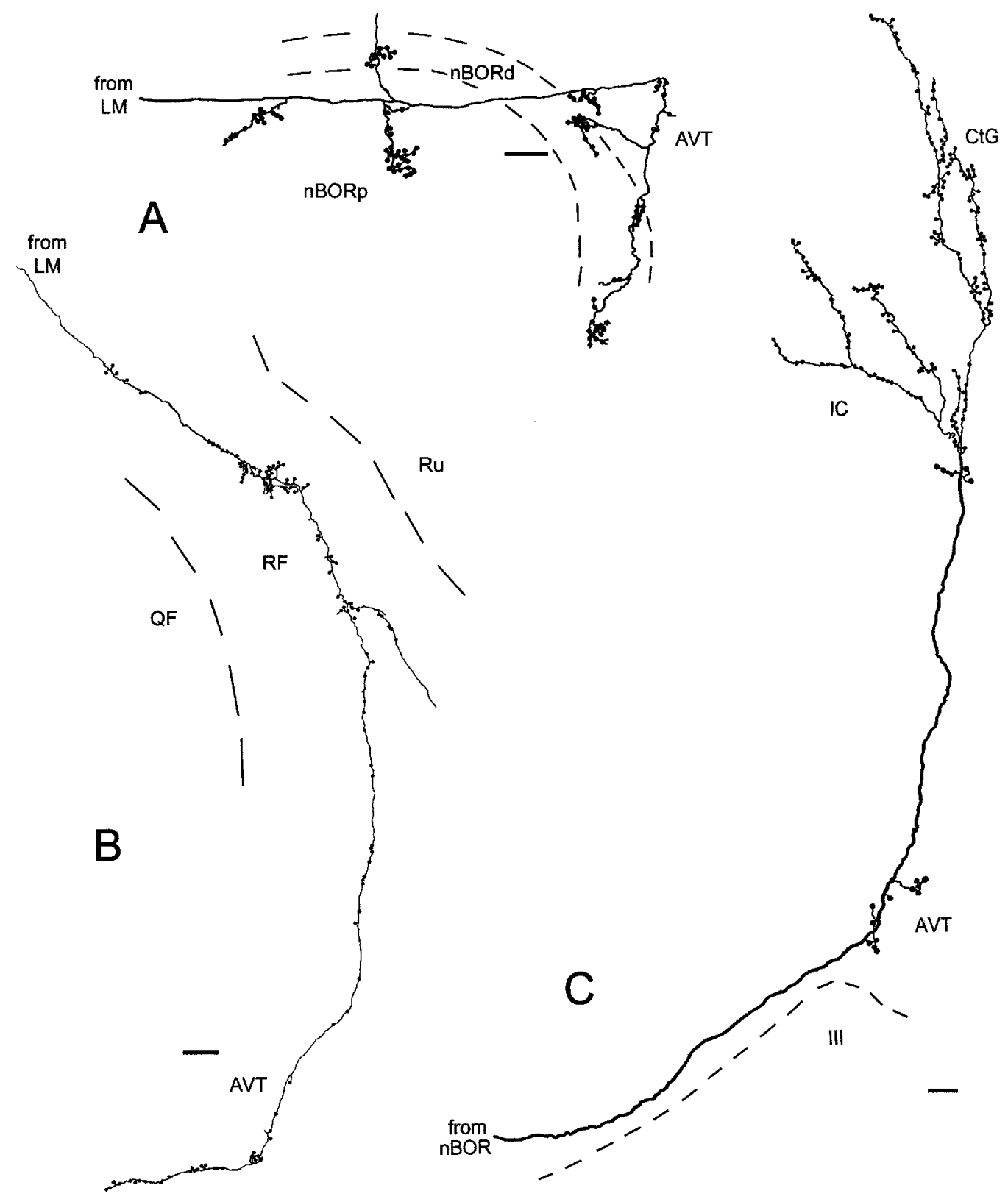

Figure 4. $A, B$, Anterogradely labeled fibers, reconstructed from serial sections, that projected from the nucleus lentiformis mesencephali ( $L M$ ) to the area ventralis of Tsai $(A V T)$. The fiber in $A$ projected heavily to the nucleus of the basal optic root $(n B O R)$, but a collateral penetrated the AVT. The fiber in $B$ descended through the reticular formation $(R F)$ where it branched and left terminals, but the parent fiber continued ventrally and terminated in the AVT. $C$ shows an anterogradely labeled fiber projecting from the nBOR to the AVT. This fiber projected heavily to nucleus ruber $(R u)$ and the accessory oculomotor area [interstitial nucleus of Cajal $(I C)$, and the central gray $(C t G)$ ], structures that are involved in postural and oculomotor control. A collateral terminated in the AVT. See legend to Figure 1 for other abbreviations. Scale bars, $60 \mu \mathrm{m}$.

tion at $5 \%$ sec (averaged from 15 sweeps). This cell preferred velocities $<5 \%$ sec but showed substantial modulation across the entire range tested $\left(0.6-20^{\circ} / \mathrm{sec}\right)$.

Of a total of 26 cells tested within the AVT, 12 showed modulation similar to that described above. Six of these cells had monocular-contralateral receptive fields. Of these six monocular cells, three preferred backward (nasal to temporal) motion, two preferred upward motion, and one preferred downward motion. The other six cells had binocular receptive fields and responded best to optic flow patterns resulting from self-translation along a particular axis. Four cells preferred translational optic flow along axes that were in the horizontal plane, and two preferred the vertical axis. Although our investigations were not systematic, the 14 cells in the AVT that were unresponsive to optic flow stimuli were also unresponsive to the movement of small visual stimuli. We also casually presented somatosensory and auditory stimuli (noise bursts), but we were unable to modulate these cells.

\section{DISCUSSION}

In the present study, using both anterograde and retrograde tracers, we have shown that the hippocampal formation receives 

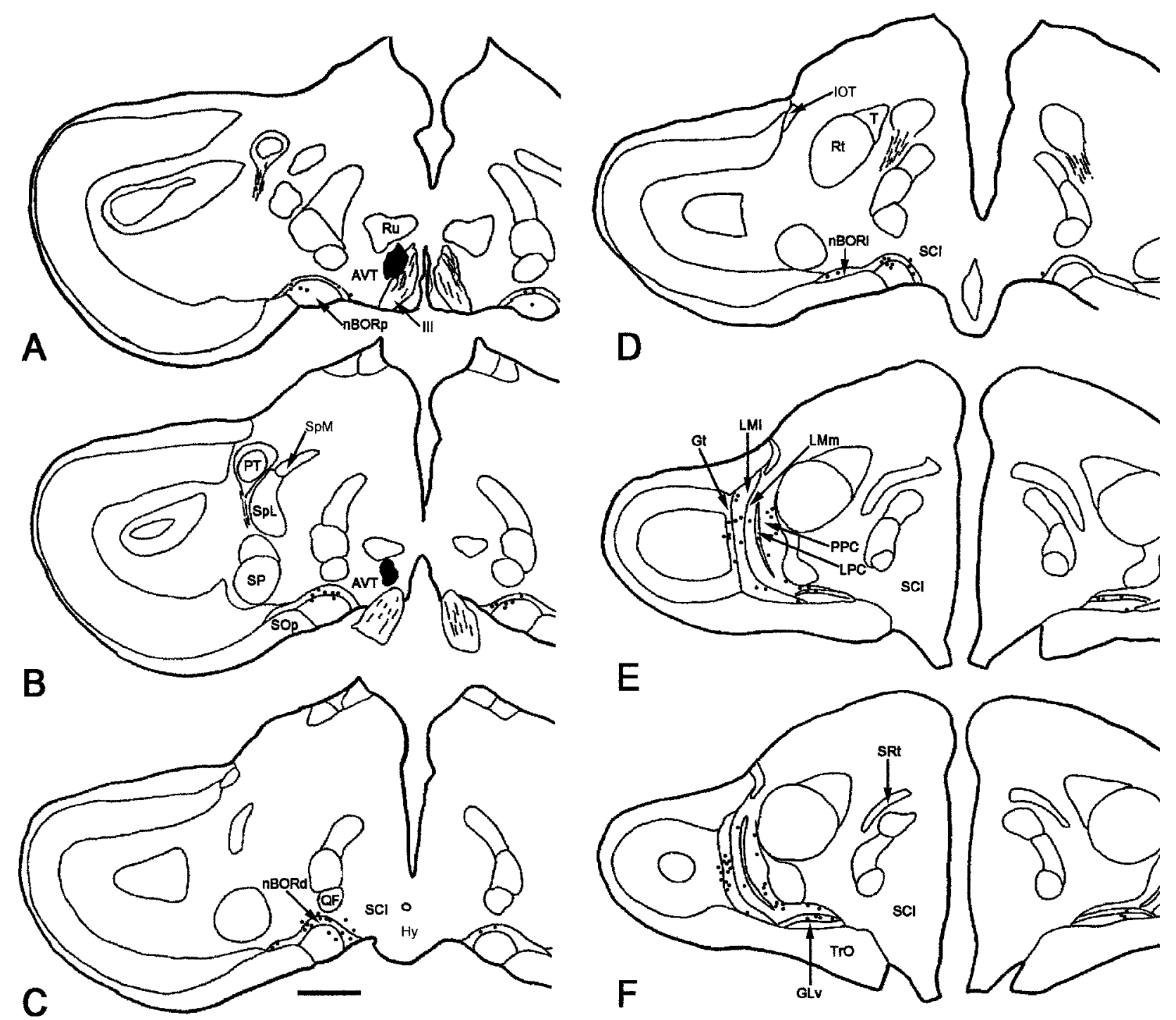

Figure 5. Retrograde labeling in the accessory optic system after injection of CTB into the area ventralis of Tsai $(A V T)$. $A-F$, Drawings of serial sections (caudal to rostral, $300 \mu \mathrm{m}$ apart) illustrating the injection site and retrograde labeling in the nucleus of the basal optic root ( $n B O R$ ) and pretectum from case AVT3. Note that the injection site, represented by the blackened area in $A$, did not include the nearby nucleus ruber $(R u)$. Labeling in the nBOR was heaviest in dorsal nBOR proper $(n B O R p)$ and the adjacent $\mathrm{nBOR}$ dorsalis $(n B O R d)$. Labeling in the pretectum was heaviest in the lateral subnucleus of lentiformis mesencephali $(L M l)$, whereas little labeling was found in the medial LM $(L M m)$ or other areas of the pretectum. Gt, Griseum tectale. See legends to Figures 1-3 for other abbreviations. Scale bar, $1 \mathrm{~mm}$.

input from the AOS, a visual pathway dedicated to the analysis of optic flow resulting from self-motion. We showed that the AVT receives input from both $\mathrm{LM}$ and $\mathrm{nBOR}$ (primarily $\mathrm{nBORd}$ ) and projects to the $\mathrm{Hp} / \mathrm{APH}$. The nBORd also provides a smaller, direct input to the Hp/APH. This pattern of connectivity suggests that the AVT is conveying optic flow information from the AOS to the $\mathrm{Hp} / \mathrm{APH}$ in pigeons. Moreover, our electrophysiological experiments showed that some cells in AVT respond to optic flow stimuli. Although our recording studies were hardly exhaustive, we did find that approximately half of those neurons tested were modulated in response to large-field visual stimuli. Of those visually sensitive neurons, half had monocular receptive fields in the contralateral eye and, as such, have visual responses similar to most neurons in the LM and nBOR (Winterson and Brauth, 1985; Wylie and Frost, 1990a, 1996). The other visually sensitive neu- rons had binocular receptive fields and responded best to flow fields resulting from self-translation along a particular axis in three-dimensional space. Such receptive field properties have been observed for neurons in the vestibulocerebellum [a projection site of the AOS (Clarke, 1977; Brecha et al., 1980)] and a subset of cells localized to nBORd (Wylie and Frost, 1990b, 1999; Wylie et al., 1998a). Thus, it is possible that some cells in the nBORd and adjacent AVT are conveying highly processed optic flow information to the $\mathrm{Hp} / \mathrm{APH}$. It is also possible that these cells are multimodal. In a 2-deoxyglucose experiment, Telford and Frost (1989) showed that nBORd, but not nBORp, responds to rotation of the pigeon in darkness. This vestibular input might arise from the lateral cerebellar nucleus, which projects heavily to nBORd but less to nBORp (Arends and Zeigler, 1991).

We must emphasize that our findings should not be reduced to 

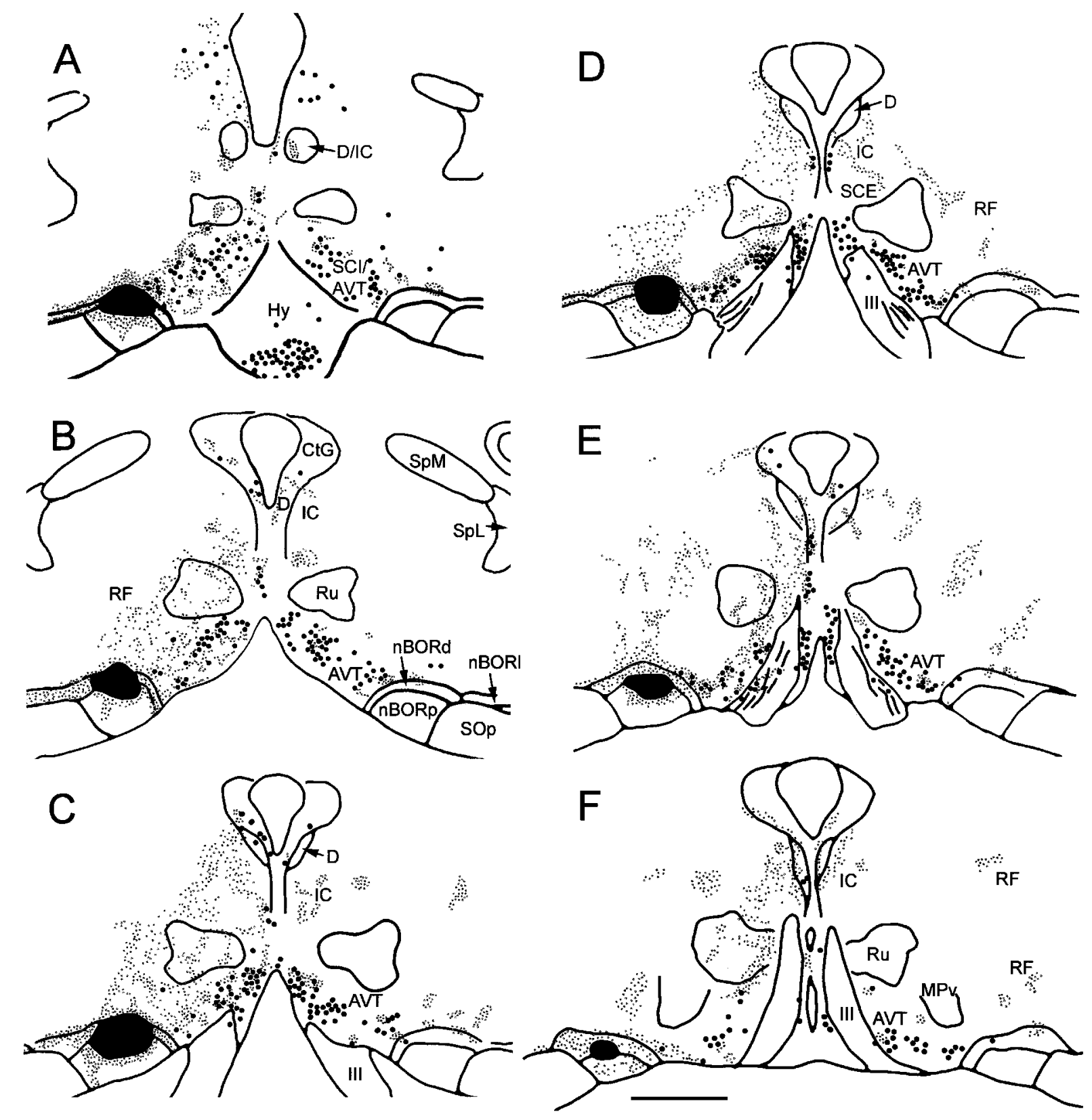

Figure 6. Results of a double labeling experiment. $A-F$, Drawings of serial sections (rostral to caudal, $\sim 130 \mu \mathrm{m}$ apart) through the area ventralis of Tsai $(A V T)$ from case DL2. The small gray dots represent the locations of anterograde terminals from an injection of biotinylated dextran amine (BDA) into the left nBOR (shaded black). The larger black dots represent retrograde-labeled cell bodies from a bilateral injection into the hippocampal formation. Note the overlap of terminal labeling and retrogradely labeled cell bodies in the AVT. See Results for additional details. See legends to Figures 1 and 3 for additional abbreviations. Scale bar, $1 \mathrm{~mm}$.

a simple demonstration of a visual input to the hippocampus. The input is from the AOS, a highly conserved visual pathway found in all vertebrates (Fite, 1985; McKenna and Wallman, 1985b; Weber, 1985) that is much neglected in the popular literature. The retinal recipient nuclei of the AOS, unlike other visual structures, are dedicated to the analysis of optic flow that result from self-motion (Frost, 1982, 1985; Frost et al., 1990, 1994). Optic flow neurons have been found in the extrastriate areas of primate visual cortex (Duffy and Wurtz, 1991), although such findings are predated by similar findings in the AOS by more than a decade (Simpson and Alley, 1974). Generally the AOS is described in reference to its importance to oculomotor function
(Simpson, 1984). We suggest additional roles for the AOS: spatial cognition, navigation, and path integration.

\section{Does the AOS provide input to the hippocampal formation in mammals?}

In mammals, the AOS consists of the medial and lateral terminal nuclei (MTN, LTN), which are functionally similar to the avian $\mathrm{nBOR}$, and the dorsal terminal nucleus and pretectal nucleus of the optic tract (collectively referred to as NOT/DTN), which are homologous to the avian LM (for review, see Simpson, 1984; Simpson et al., 1988b; Grasse and Cynader, 1990). The MTN, LTN, and DTN project to an area in the ventral tegmentum 

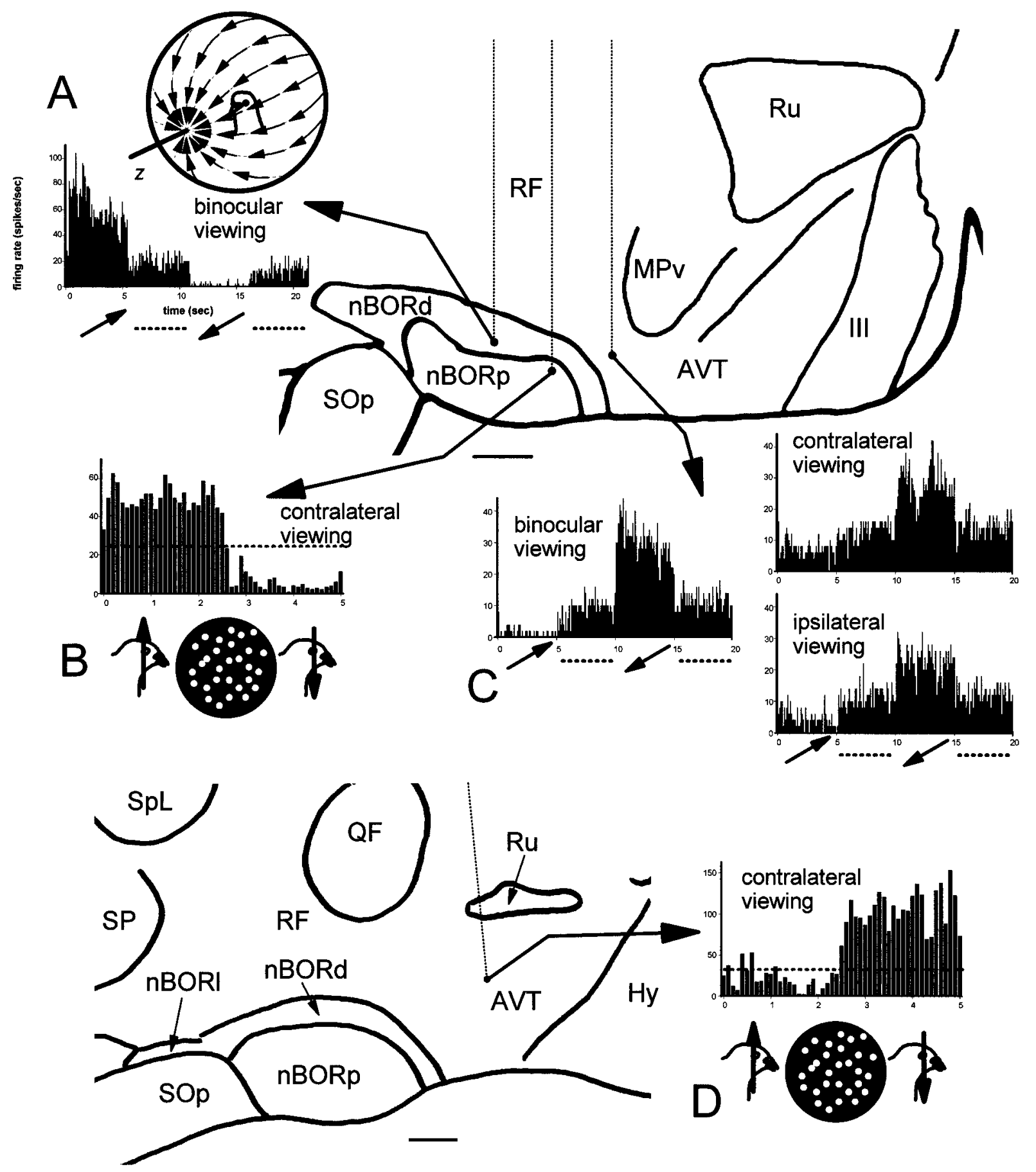

Figure 7. Responses of neurons in the nucleus of the basal optic root $(n B O R)$ and area ventralis of Tsai $(A V T)$ to large-field visual stimulation. This figure shows the locations (black circles) of four isolated neurons, all from the same bird, and their responses to large-field stimulation $(A-D)$. The locations are shown on two serial sections through the basal mesencephalon. The upper section was located $\sim 0.5 \mathrm{~mm}$ caudal to the lower section. The broken vertical lines indicate the electrode tracks. The neurons shown in $B$ and $D$ had large monocular receptive fields in the contralateral eye. The PSTHs show the responses to large-field motion oscillating upward and downward ( $2.5 \mathrm{sec}$ up, $2.5 \mathrm{sec}$ down) in the contralateral hemifield. The broken horizontal lines represent the spontaneous rates. The neuron in $B$, which was located in the nBOR proper (nBORp), was maximally excited by upward large-field motion and inhibited by downward motion. The neuron in $D$, which was located in the rostral AVT, had the opposite direction preference. The neurons shown in $A$ and $C$ had binocular receptive fields and preferred horizontal large-field motion in both hemifields. The PSTHs show the responses of these neurons to a translational flow field simulating self-translation of the bird along the $z$-axis (i.e., forward and backward self-translation). In $A$ a schematic of the flow field that results in self-translation backward along the $z$-axis is shown. It is best described as forward optic flow contracting to a point directly in front. For each sweep the sequence was as follows: (1) $\sim 5 \mathrm{sec}$ of backward optic flow (which would result from forward translation), (2) a 5 sec pause (broken line), (3) $5 \mathrm{sec}$ of forward optic flow, (4) a $5 \mathrm{sec}$ pause. In $A$ and $C$ the responses to binocular stimulation are shown. The responses to monocular stimulation of the ipsilateral and contralateral hemifields are also shown for the neuron in $C$. The neuron in $A$, which was located in the nBOR dorsalis $(n B O R d)$ was maximally excited/inhibited by backward/forward optic flow along this axis. The neuron in $C$, which was found in the AVT, showed the opposite direction preference. Note that greater modulation occurred under conditions of binocular viewing, compared with stimulation of either eye alone. See legends to Figures 1 and 3 for additional abbreviations. Scale bars, $300 \mu \mathrm{m}$. 
known as the visual tegmental relay zone (VTRZ) (Giolli et al., 1984, 1988). Cells in the VTRZ of rabbits respond to optic flow stimuli but have higher order properties than cells in the NOT/ DTN, LTN, and MTN. Like cells in the LM and nBORp, cells in the NOT/DTN, MTN, and LTN respond to large-field stimuli moving in a particular direction in the contralateral visual field (Soodak and Simpson, 1988). Like cells in the avian nBORd, some cells in the VTRZ have binocular receptive fields and encode rotational flow fields (Simpson et al., 1988a). The VTRZ, now recognized in the rat stereotaxic atlas (Paxinos and Watson, 1986), is a thin layer of cells that resides in the dorsal part of the ventral tegmental area (VTA; AVT in birds), just ventral to the $\mathrm{Ru}$. The VTRZ is distinguished as the area that provides a massive input to the optic flow-sensitive areas of the inferior olive (Giolli et al., 1985; Simpson et al., 1988a,b). In birds, the major input to the optic flow areas of the inferior olive is from nBORd (Brecha et al., 1980).

In mammals, the VTA projects to the hippocampus, but does part of this projection originate from the VTRZ? In a recent retrograde tracing study, Gasbarri et al. (1994) showed that both dopaminergic and nondopaminergic neurons were labeled throughout VTA after injections into the CA1 region of the hippocampus. Gasbarri et al. (1994) did not distinguish VTRZ from the rest of the VTA in their drawings, but there was heavy labeling in the dorsal VTA just ventral to the red nucleus (Gasbarri et al., 1994, their Figs. 1A,B, 2A,B). We are certain that these cells are within the VTRZ. Thus, it seems that the nBORd to $\mathrm{Hp} / \mathrm{APH}$ pathway revealed in the present study exists in mammals, but it has simply been overlooked. A double labeling study like the one we have performed here is necessary to confirm this pattern of connectivity in mammals.

\section{The hippocampus, spatial memory, and path integration}

Lesion studies of the $\mathrm{Hp}$ resulting in performance deficits in tasks such as the Morris water maze in rats and homing behavior in pigeons have implicated the $\mathrm{Hp}$ in spatial memory processes, including navigation (Morris et al., 1982; Sutherland et al., 1982; Bingman et al., 1990; Nadel, 1991; Bingman and Yates, 1992; Sherry et al., 1992; Poucet, 1993). However, the answer to the question of how the representation of space is established in the Hp remains elusive. O'Keefe and Nadel (1978) postulated that the Hp forms a "cognitive map" of the environment. Central to this idea was the discovery of "place cells" that are selectively active when an animal is in a particular location (O'Keefe and Dostrovsky, 1971; O'Keefe, 1979; Muller, 1996; O’Keefe and Burgess, 1996). A substantial body of research emphasizes how the relationship of external landmarks, i.e., allothetic cues, is represented by the activity of place cells (O'Keefe and Nadel, 1978; for review, see Poucet, 1993; McNaughton et al., 1996; Whishaw et al., 1997). More recently, studies have emphasized that self-motion or ideothetic information is also important for place-cell activity (Foster et al., 1989; Wilson and McNaughton, 1993; McNaughton et al., 1995, 1996), and as such it is thought that the Hp is involved in path integration (Whishaw et al., 1997; Whishaw and Maaswinkel, 1998).

In the hippocampal formation and afferent structures, many neurons are tuned to the directional heading in the horizontal plane. These "head direction cells" have been found in the postsubiculum (Taube et al., 1990a) and posterior cortex (Chen et al., 1994) as well the anterior thalamus (Taube, 1995) and lateral dorsal thalamus (Mizumori and Williams, 1993). Both allothetic and ideothetic cues affect the firing of head direction cells (Taube et al., 1990b; Chen et al., 1994; Knierim et al., 1995; Blair and Sharp, 1996), and it is thought that the ideothetic information arises from the vestibular system (McNaughton et al., 1995, 1996; Muller et al., 1996).

The results of the present study are consistent with the idea that the hippocampal formation is involved in path integration by the analysis of ideothetic cues resulting from self-motion, but we propose an additional ideothetic cue: optic flow. The optic flow reaches the hippocampal formation from the AOS. Until now, the AOS has not been considered a player in spatial cognition but is generally regarded as a slave to the oculomotor system.

\section{REFERENCES}

Arends JJA, Zeigler HP (1991) Organization of the cerebellum in the pigeon (Columba livia): II. Projections of the cerebellar nuclei. J Comp Neurol 306:245-272.

Bingman VP, Yates G (1992) Hippocampal lesions impair navigational learning in experienced homing pigeons. Behav Neurosci 106:229-232.

Bingman VP, Ioale P, Casini G, Bagnoli P (1990) The avian hippocampus: evidence for a role in the development of the homing pigeon navigational map. Behav Neurosci 104:906-911.

Blair HT, Sharp PE (1996) Visual and vestibular influences on headdirection cells in the anterior thalamus of the rat. Behav Neurosci 110:643-660.

Brecha N, Karten HJ, Hunt SP (1980) Projections of the nucleus of basal optic root in the pigeon: an autoradiographic and horseradish peroxidase study. J Comp Neurol 189:615-670.

Burns S, Wallman J (1981) Relation of single unit properties to the oculomotor function of the nucleus of the basal optic root (AOS) in chickens. Exp Brain Res 42:171-180.

Casini G, Bingman VP, Bagnoli P (1986) Connections of the pigeon dorsomedial forebrain studied with WGA-HRP and $\mathrm{H}$ proline. J Comp Neurol 245:454-470.

Chen LL, Lin L-H, Barnes CA, McNaughton BL (1994) Head-direction cells in the rat posterior cortex. II. Contributions of visual and ideothetic information to the directional firing. Exp Brain Res 101:24-34.

Clarke PGH (1977) Some visual and other connections to the cerebellum of the pigeon. J Comp Neurol 174:535-552.

Duffy CJ, Wurtz RH (1991) Sensitivity of MST neurons to optic flow stimuli. I. A continuum of response selectivity to large-field stimuli. J Neurophysiol 65:1329-1345.

Fite KV (1985) Pretectal and accessory-optic visual nuclei of fish, amphibia and reptiles: theme and variations. Brain Behav Evol 26:192-202.

Fite KV, Brecha N, Karten HJ, Hunt SP (1981) Displaced ganglion cells and the accessory optic system of the pigeon. J Comp Neurol 195:279-288.

Foster TC, Castro CA, McNaughton BL (1989) Spatial selectivity of rat hippocampal neurons: dependence on preparedness for movement. Science 244:1580-1582.

Frost BJ (1982) Mechanisms for discriminating object motion from selfinduced motion in the pigeon. In: Analysis of visual behavior (Ingle DJ, Goodale MA, Mansfield JW, eds), pp 177-196. Cambridge, MA: MIT.

Frost BJ (1985) Neural mechanisms for detecting object motion and figure-ground boundaries contrasted with self-motion detecting systems. In: Brain mechanisms of spatial vision (Ingle D, Jeannerod M, Lee D, eds), pp 415-449. Dordrecht, The Netherlands: Martinus Nijhoft.

Frost BJ, Wylie DR, Wang Y-C (1990) The processing of object and self-motion in the tectofugal and accessory optic pathways of birds. Vision Res 30:1677-1688.

Frost BJ, Wylie DR, Wang Y-C (1994) The analysis of motion in the visual systems of birds. In: Perception and motor control in birds (Green P, Davies M, eds), pp 249-266. Berlin: Springer. 
Gamlin PDR, Cohen DH (1988a) The retinal projections to the pretectum in the pigeon (Columba livia). J Comp Neurol 269:1-17.

Gamlin PDR, Cohen DH (1988b) Projections of the retinorecipient pretectal nuclei in the pigeon (Columba livia). J Comp Neurol 269:18-46.

Gasbarri A, Verney C, Innocenzi R, Campana E, Pacitti C (1994) Mesolimbic dopaminergic neurons innervating the hippocampal formation in the rat: a combined retrograde tracing and immunohistochemical study. Brain Res 668:71-79.

Gibson JJ (1950) The perception of the visual world. Boston: Houghton Mifflin.

Gibson JJ (1954) The visual perception of objective motion and subjective movement. Psychol Rev 64:304-314.

Giolli RA, Blanks RHI, Torigoe Y (1984) Pretectal and brain stem projections of the medial terminal nucleus of the accessory optic system of the rabbit and rat as studied by anterograde and retrograde neuronal tracing methods. J Comp Neurol 227:228-251.

Giolli RA, Blanks RHI, Torigoe Y, Williams DD (1985) Projections of the medial terminal nucleus, ventral tegmental nuclei and substantia nigra of rabbit and rat as studied by retrograde axonal transport of horseradish peroxidase. J Comp Neurol 227:228-251.

Giolli RA, Torigoe Y, Blanks RHI, MacDonald HM (1988) Projections of the dorsal and lateral terminal accessory optic nuclei system and of the interstitial nucleus of the superior fasciculus (posterior fibers) in the rabbit and rat. J Comp Neurol 277:608-620.

Graf W, Simpson JI, Leonard CS (1988) Spatial organization of visual messages of the rabbit's cerebellar flocculus. II. Complex and simple spike responses of Purkinje cells. J Neurophysiol 60:2091-2121.

Grasse KL, Cynader MS (1990) The accessory optic system in frontaleyed animals. In: Vision and visual dysf unction, Vol IV, The neuronal basis of visual function (Leventhal A, ed), pp 111-139. New York: MacMillan.

Karten HJ, Hodos W (1967) A stereotaxic atlas of the brain of the pigeon (Columba livia). Baltimore: Johns Hopkins.

Karten HJ, Fite KV, Brecha N (1977) Specific projection of displaced retinal ganglion cells upon the accessory optic system in the pigeon (Columba livia). Proc Natl Acad Sci USA 74:1752-1756.

Knierim JJ, Kudrimoti HS, McNaughton BL (1995) Place cells, head direction cells, and the learning of landmark stability. J Neurosci 15:1648-1659.

Leonard CS, Simpson JI, Graf W (1988) Spatial organization of visual messages of the rabbit's cerebellar flocculus. I. Typology of inferior olive neurons of the dorsal cap of Kooy. J Neurophysiol 60:2073-2090.

Luppi P, Fort P, Jouvet M (1990) Iontophoretic application of unconjugated cholera toxin $\mathrm{B}$ subunit $(\mathrm{Ctb})$ combined with immunohistochemistry of neurochemical substances: a method for transmitter identification of retrogradely labelled neurons. Brain Res 534:209-224.

McKenna O, Wallman J (1981) Identification of avian brain regions responsive to retinal slip using 2-deoxyglucose. Brain Res 210:455-460.

McKenna O, Wallman J (1985a) Functional postnatal changes in avian brain regions responsive to retinal slip: a 2-deoxy-D-glucose study. J Neurosci 5:330-342.

McKenna O, Wallman J (1985b) Accessory optic system and pretectum of birds: comparisons with those of other vertebrates. Brain Behav Evol 26:91-116.

McNaughton BL, Knierim JJ, Wilson MA (1995) Vector encoding and the vestibular foundations of spatial cognition: neurophysiological and computational mechanisms. In: The cognitive neurosciences (Gazzaniga MS, ed), pp 585-595. Cambridge, MA: MIT.

McNaughton BL, Barnes CA, Gerrard JL, Gothard K, Jung MW, Knierim JJ, Kudrimoti H, Qin Y, Skaggs WE, Suster M, Weaver KL (1996) Deciphering the hippocampal polyglot: the hippocampus as a path integration system. J Exp Biol 199:173-185.

Mittelstaedt ML, Mittelstaedt H (1980) Homing by path integration in a mammal. Naturwissenschaften 67:566-567.

Mizumori SJY, Williams JD (1993) Directionally selective mnemonic properties of neurons in the lateral dorsal nucleus of the thalamus of rats. J Neurosci 13:4015-4028.

Morris RGM, Garrud P, Rawlings J, O'Keefe J (1982) Place navigation impaired in rats with hippocampal lesions. Nature 279:681-683.

Muller RU (1996) A quarter century of place cells. Neuron 17:813-822.

Muller RU, Ranck Jr JB, Taube JS (1996) Head direction cells: properties and functional significance. Curr Opin Neurobiol 6:196-206.

Nadel L (1991) Forum: is the hippocampal formation preferentially involved in spatial behaviour? Hippocampus 1:221-292.
O'Keefe J (1979) A review of the hippocampal place cells. Prog Neurobiol 13:419-439.

O'Keefe J, Burgess N (1996) Geometric determinants of the place fields of hippocampal neurons. Nature 381:425-428.

O'Keefe J, Dostrovsky J (1971) The hippocampus as a spatial map. Preliminary evidence from unit activity in the freely moving rat. Brain Res 34:171-175.

O'Keefe J, Nadel L (1978) The hippocampus as a cognitive map. Oxford: Clarendon.

Paxinos G, Watson C (1986) The rat brain in stereotaxic coordinates, Ed 2. Sydney: Academic.

Poucet B (1993) Spatial cognitive maps in animals; new hypotheses on their structure and neural mechanisms. Psychol Rev 100:163-182.

Reiner A, Brecha N, Karten HJ (1979) A specific projection of retinal displaced ganglion cells to the nucleus of the basal optic root in the chicken. Neuroscience 4:1679-1688.

Sharp PE, Blair HT, Etkin D, Tzanetos DB (1995) Influences of vestibular and visual motion information on the spatial firing patterns of hippocampal place cells. J Neurosci 15:173-189.

Sherry DF, Jacobs LF, Gaulin SJC (1992) Spatial memory and adaptive specialization of the hippocampus. Trends Neurosci 15:298-302.

Simpson JI (1984) The accessory optic system. Annu Rev Neurosci $7: 13-41$.

Simpson JI, Alley K (1974) Visual climbing fiber input to rabbit vestibulocerebellum: a source of direction-specific information. Brain Res 82:302-308.

Simpson JI, Giolli RA, Blanks RHI (1988a) The pretectal nuclear complex and the accessory optic system. In: Neuroanatomy of the oculomotor system (Buttner-Ennever JA, ed), pp 335-364. Amsterdam: Elsevier.

Simpson JI, Leonard CS, Soodak RE (1988b) The accessory optic system of rabbit. II. Spatial organization of direction selectivity. J Neurophysiol 60:2055-2072.

Soodak RE, Simpson JI (1988) The accessory optic system of rabbit. I. Basic response properties. J Neurophysiol 60:2037-2054.

Sutherland RJ, Whishaw IQ, Kolb B (1982) Spatial mapping: definitive disruption by hippocampal or medial frontal cortical damage in the rat. Neurosci Lett 31:271-276.

Taube JS (1995) Head direction cells recorded in anterior thalamic nuclei of freely moving rats. J Neurosci 15:70-86.

Taube JS, Muller RU, Ranck JB (1990a) Head-direction cells recorded from the postsubiculum in freely moving rats. I. Description and quantitative analysis. J Neurosci 10:420-435.

Taube JS, Muller RU, Ranck JB (1990b) Head-direction cells recorded from the postsubiculum in freely moving rats. II. Effects of environmental manipulations. J Neurosci 10:436-447.

Telford L, Frost BJ (1989) Functional activity in the accessory optic system during visual, vestibular and visual-vestibular stimulation in the pigeon. Exp Brain Res 77:391-397.

Weber JT (1985) Pretectal complex and accessory optic system in alert monkeys. Brain Behav Evol 26:117-140.

Whishaw IQ, Maaswinkel H (1998) Rats with fimbria-fornix lesions are impaired in path integration: a role for the hippocampus in sense of direction. J Neurosci 18:3050-3058.

Whishaw IQ, McKenna JE, Maaswinkel H (1997) Hippocampal lesions and path integration. Curr Opin Neurobiol 7:228-234.

Wild JM (1989) Pretectal and tectal projections to the homologue of the dorsal lateral geniculate nucleus in the pigeon: an anterograde and retrograde tracing study with cholera toxin conjugated to horseradish peroxidase. Brain Res 479:130-137.

Wild JM (1992) Direct and indirect "cortico"-rubral and rubrocerebellar cortical projections in the pigeon. J Comp Neurol 326:623-636.

Wild JM (1993) Descending projections of the songbird nucleus robustus archistrialis. J Comp Neurol 338:225-241.

Wilson MA, McNaughton BL (1993) Dynamics of the hippocampal ensemble code for space. Science 261:1055-1058.

Winterson BJ, Brauth SE (1985) Direction-selective single units in the nucleus lentiformis mesencephali of the pigeon (Columba livia). Exp Brain Res 60:215-226.

Wylie DR, Frost BJ (1990a) Visual response properties of neurons in the nucleus of the basal optic root of the pigeon: a quantitative analysis. Exp Brain Res 82:327-336.

Wylie DR, Frost BJ (1990b) Binocular neurons in the nucleus of the 
basal optic root (nBOR) of the pigeon are selective for either translational or rotational visual flow. Vis Neurosci 5:489-495.

Wylie DR, Frost BJ (1991) Purkinje cells in the vestibulocerebellum of the pigeon respond best to either rotational or translational visual flow. Exp Brain Res 86:229-232.

Wylie DR, Frost BJ (1993) Responses of pigeon vestibulocerebellar neurons to optokinetic stimulation: II. The 3-dimensional reference frame of rotation neurons in the flocculus. J Neurophysiol 70:2632-2646.

Wylie DRW, Frost BJ (1996) The pigeon optokinetic system: visual input in extraocular muscle coordinates. Vis Neurosci 13:945-953.

Wylie DRW, Frost BJ (1999) Responses of neurons in the nucleus of the basal optic root to translational and rotational flowfields. J Neurophysiol 81:267-276.
Wylie DRW, Linkenhoker B (1996) Mossy fibres from the nucleus of the basal optic root project to the vestibular and cerebellar nuclei in pigeons. Neurosci Lett 219:83-86.

Wylie DRW, Linkenhoker B, Lau K (1997) Projections of the nucleus of the basal optic root in pigeons (Columba livia). J Comp Neurol 384:517-536.

Wylie DRW, Bischof WF, Frost BJ, (1998a) Common reference frame for neural coding of translational and rotational optic flow. Nature 392:278-282.

Wylie DRW, Glover RG, Lau KL (1998b) Projections from the accessory optic system and pretectum to the dorsolateral thalamus in the pigeon (Columba livia): a study using both anterograde and retrograde tracers. J Comp Neurol 391:456-469. 